\title{
Validity of the Demirjian and Fishman Methods for Predicting Chronological Age Amongst Yemeni Children
}

"Maktoom A. Alqadi and Amal H. Abuaffan

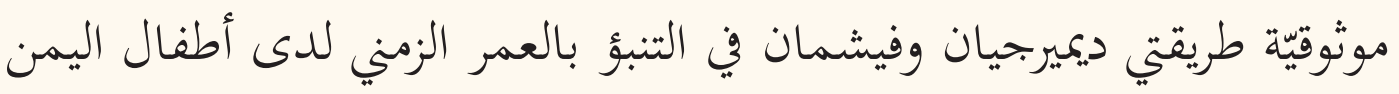

مكتوم القاضي و آمال أبو عفان

ABSTRACT: Objectives: There has been an increasing need for reliable chronological age (CA) estimation in several aspects, including orthodontic treatment needs and legal, civil and forensic purposes. This study aimed to assess the validity of the Demirjian and Fishman methods in predicting the CA of Yemeni children. Methods: This descriptive cross-sectional study was conducted at seven schools in Sana'a, Yemen, between December 2016 and December 2017. One orthopantomograph and one left hand-wrist X-ray were obtained for each child to calculate the dental age (DA) and skeletal age (SA) which were correlated and compared with the CA. Results: A total of 358 Yemeni children aged $8-16$ years were included in this study. The mean CA, DA and SA were $12.00 \pm 2.25,11.34 \pm 2.42$ and $12.39 \pm 1.65$ years, respectively. The Demirjian method significantly underestimated the CA by $0.58 \pm 1.25$ years in the total sample and $0.73 \pm 1.30$ and $0.40 \pm 1.17$ years in males and females, respectively $(P<0.001)$. The Fishman method significantly underestimated the CA by $0.23 \pm 1.19$ and $0.44 \pm 1.26$ years in the total sample and in males, respectively $(P \leq 0.02)$. The Fishman method insignificantly underestimated the females CA by $0.02 \pm 1.08$ years $(P=0.898)$. Conclusions: Yemeni CA is highly correlated to DA and SA estimated by the Demirjian and Fishman methods, respectively. The Fishman method was more accurate amongst Yemeni females. Results showed that Yemeni children are delayed in dental development and skeletal maturity.

Keywords: Age Determination by Teeth; Age Determination by Skeleton; Children; Adult Children; Diagnostic Imaging; Yemen.

الملخص: الههف: هناك حاجة متزايدة لتقدير العمر الزمني الموثوق من عدة جوانب. وهذه تتضمن احتياجات علاج تقويم الأسنان

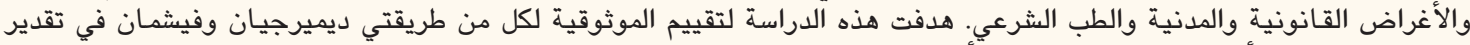

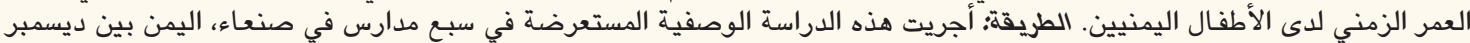

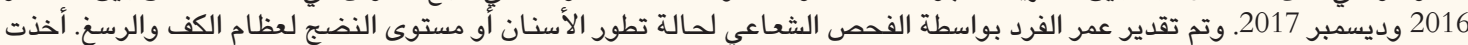

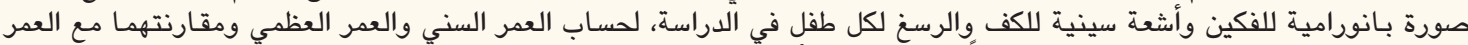

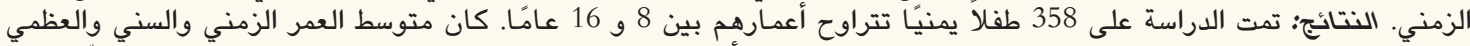

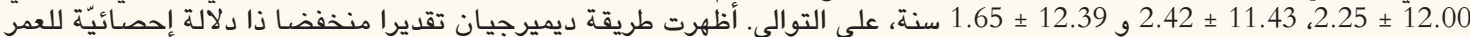

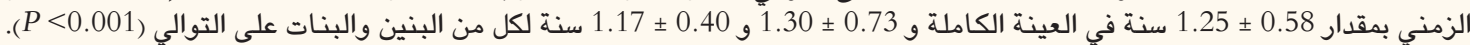

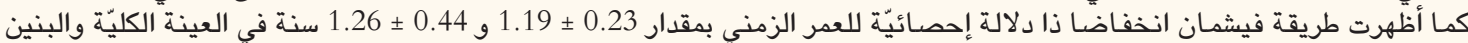

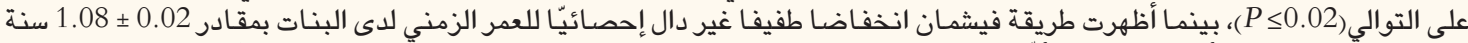
و وطريقة

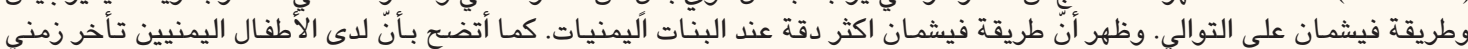

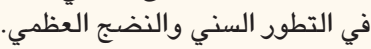

$$
\text { الكلمات المفتاحية؛ العمر السني؛ العمر العظمي؛ أطفال؛ أطفال بالغين؛ التصوير التشخيصي؛ اليمن. }
$$

\section{ADVANCES IN KNOWLEDGE}

Yemeni children are delayed in skeletal maturation and dental development in relation to Demirjian and Fishman standards.

To the best of the authors' knowledge, this is the first study investigating the applicability of chronological age estimating methods in the Yemeni population

\section{Application to Patient Care}

Orthodontists should not rely on Yemeni chronological age to assign the proper age for growth modification using functional appliances.

The Demirjian and Fishman methods are not applicable for clinical orthodontic implementations but can be acceptable for legal, civil and forensic purposes. 
$\mathrm{P}$ REDICTION OF CHRONOLOGICAL AGE (CA) HAS become important for orthodontic diagnosis and treatment as well as for civil purposes. ${ }^{1,2}$ Different methods have been suggested to predict the CA based on skeletal maturity or dental development. ${ }^{3,4}$ Dental and skeletal age estimation methods are valuable approaches in predicting the CA when birth data are missing. ${ }^{5}$ The validity of these methods will have clinical importance in the reliability of orthodontic diagnosis and treatment planning.

The Demirjian method is a dental age (DA) estimating technique which uses a radiographic assessment of dental development of the left mandibular teeth, excluding the third molar. ${ }^{4}$ Several studies have been conducted to assess the applicability of the Demirjian method to predict the CA amongst different populations; the method has shown an overestimation of CA of Turkish, Indian and Saudi children and an underestimation of Tunisian, Kuwaiti and Chinese children. ${ }^{6-11}$ However, the Demirjian method has been accurate in CA prediction for Sudanese and Omani children. ${ }^{12,13}$ Jayaraman et al. found that the Demirjian method tends to overestimate the age of both genders (overestimation of 0.60 and 0.65 years for males and females, respectively). ${ }^{14}$

The Fishman method is based on skeletal maturity indicators (SMI) and is widely used to estimate the skeletal age (SA) by hand-wrist X-ray. ${ }^{3}$ The SA is closely related to child growth and considered to be the most reliable method for assessing maturation status, although affected by ethnicity. ${ }^{15,16}$ Definite variations between genders and races were found in the CA and in the timing of skeletal maturity. The SMI method, which is related to the overall maxillofacial growth velocity, was found to have high discriminant validity between individuals' pubertal stages and is clinically acceptable to predict the peak growth of the mandible. ${ }^{17,18}$ However, studies aimed at validating the SMI method for predicting the CA showed inconsistent results. ${ }^{19-21}$ The Fishman method was accurate when predicting the CA of Indian children and was inaccurate for Indonesian and Lebanese children; this method was more accurate when compared to the Demirjian method. ${ }^{19-21}$

The applicability of the Demirjian and/or Fishman methods will help to accurately determine the CA of children without a birth certificate for functional orthodontic intervention without the need of hand-wrist radiographs. To the best of the authors' knowledge, no study has been conducted on Yemeni children to investigate the applicability of the Demirjian, Fishman or any age estimating methods. This study aimed to validate the Fishman and Demirjian methods in predicting the CA of Yemeni children.

\section{Methods}

This descriptive cross-sectional study was conducted between December 2016 and December 2017. Participants were aged 8-16 years, resided in Sana'a, Yemen, and both parents were Yemeni. The exclusion criteria for this study were as follows: 1) presence of any congenital, nutritional or systemic disorder; 2) presence of periapical lesion or trauma to the lower jaw or left handwrist; 3) congenitally missing or supernumerary teeth; and 4) children who were at the time or had previously had orthodontic or oral surgical treatment. The sample size was calculated using the following equation:

$$
n=\frac{2\left(Z_{1-\frac{\alpha}{2}}+Z_{1-\beta}\right)^{2}}{(\bar{d} / S D) 2} \quad \text { [Equation 1] }
$$

Where $\alpha$ is the type one error (probability of rejecting true hypothesis) set at $0.05, Z_{1-\frac{\alpha}{2}}$ is the critical value from standard normal distribution table set at $1.96,1-\beta$ is the power of the test sets at $80 \%, Z_{1-\beta}$ is the critical value from standard normal distribution table set as $0.84, \bar{d}$ is the difference in means for matched groups and SD is the standard deviation calculated from a previous study. 22

The sample size was calculated based on a previous study conducted on a Turkish population. ${ }^{22}$ Therefore, the effective minimum sample size calculated was 238 children [Equation 1]. The sample in the current study was increased to a total of 358 children for more precision and collected via a cluster random sampling technique in three out of the ten directorates of Sana'a. Two public schools from the first directorate, two public schools from the second directorate and three private schools from the third directorate were randomly selected by the authors and the head office of education in Sana'a. Students from each school were conveniently sampled and stratified according to age and gender, with a one year interval [Table 1].

Table 1: Distribution of the study sample according to age and gender $(\mathrm{N}=358)$

\begin{tabular}{lccc}
$\begin{array}{l}\text { Age group in years } \\
\text { (age range) }\end{array}$ & Male & Female & Total \\
\hline $8(8-8.999)$ & $21(10.9)$ & $23(13.9)$ & $44(12.3)$ \\
$9(9-9.999)$ & $17(8.8)$ & $18(10.9)$ & $35(9.8)$ \\
$10(10-10.999)$ & $28(14.5)$ & $21(12.7)$ & $49(13.7)$ \\
$11(11-11.999)$ & $35(18.1)$ & $24(14.5)$ & $59(16.5)$ \\
$12(12-12.999)$ & $29(15)$ & $22(13.3)$ & $51(14.2)$ \\
$13(13-13.999)$ & $21(10.9)$ & $21(12.7)$ & $42(11.7)$ \\
$14(14-14.999)$ & $16(8.3)$ & $14(8.5)$ & $30(8.4)$ \\
$15(15-15.999)$ & $26(13.5)$ & $22(13.3)$ & $48(13.4)$ \\
Total & $193(53.9)$ & $165(46.1)$ & $358(100)$
\end{tabular}


One orthopantomograph (OPG) and one left handwrist radiograph (HWR) were obtained for each child by the same operator and with the same machine (PaxFlex3D, Vatech, Republic of Korea) in accordance with the manufacturer's instructions. All X-rays were assessed for their anatomical clearness and for age prediction by the authors. The date of birth of each child was obtained from the child's birth certificate. The CA was calculated in years by subtracting the date of birth from the date of radiographing divided by 365 .

The DA was calculated according to the Demirjian method from the digital OPG. Each of the seven lower left teeth, excluding the third molar, was represented by a letter $(\mathrm{A}-\mathrm{H})$ based on its developmental stage. ${ }^{4}$ Each letter was matched with its specific self-weighted score in tooth gender-specific tables. The total score of the seven teeth was converted to DA according to the gender-specific tables of the Demirjian method. ${ }^{4}$

The SA was calculated in accordance with the Fishman method. Each child's left HWR was assessed for assignment of the SMI, as shown in a scheme suggested by Fishman. ${ }^{3}$ The assigned SMI was matched to the corresponding SA. The first stage of skeletal maturation in the Fishman method using the SMI of the proximal phalanx of the third finger (PP3) begins at ages 11.01 and 9.94 years for males and females, respectively. The lower limit of the childrens' ages in this study was eight years; the children who did not reach the lower limit for PP3 stage were excluded from statistical comparisons because they cannot be scored by the Fishman method. The data were statistically described and analysed with the Statistical Package for the Social Sciences (SPSS), Version 21 (IBM Corp., Armonk, New York, USA).

Descriptive statistics were determined for the total CA, DA and SA. Comparative analysis was conducted for the assessment of the statistically significant differences between the means for the children and within age groups for both genders. The Kolmogorov-Smirnov test showed a non-normal distribution of data. Nonparametric tests were used for the correlation and comparison among the measurement methods within age groups and by genders. A value of $P<0.05$ was considered statistically significant. In addition, the CA was subtracted from the DA and SA. A positive value indicated overestimation, whereas a negative value indicated an underestimation of CA by the method.

Regression models were used to predict the CA by DA and SA. After six weeks, 60 randomly selected participants were rescored to evaluate the reliability of the Demirjian and Fishman methods by using the Dahlberg equation.

An ethical approval was obtained from the Faculty of Dentistry, University of Khartoum, Khartoum, Sudan as this study was part of a doctoral thesis. Letters were sent by the author via the selected schools to children's parents to be signed for informed consent.

\section{Results}

A total of 358 Yemeni children were included in this study. The mean CA for the total sample was $12.00 \pm 2.25$ years $(12.06 \pm 2.24$ years for males and $11.94 \pm 2.46$ years for females). The lowest mean age of $11.43 \pm 2.42$ years for the total sample was found using the Demirjian method $(11.33 \pm 2.40$ and $11.54 \pm 2.46$ years for males and females, respectively), whereas the highest mean age of $12.39 \pm 1.65$ years was noted using the Fishman method $(12.53 \pm 1.50$ and $12.25 \pm 1.77$ years for males and females, respectively).

A Wilcoxon signed-rank test showed significant differences between the CA and SA for males $(P=0.001)$ and between the CA and DA for both genders $(P<0.001$ each) [Table 2]. The CA for males was underestimated by both methods, yet the Fishman method was closer to the CA than the Demirjian method $(-0.44 \pm 1.26$ versus $-0.73 \pm 1.30 ; P \leq 0.001)$. For females, the DA showed a significant age underestimation $(P<0.001)$, while no significant difference was noted between the CA and SA $(P=0.898)$. Intraclass correlation coefficient (ICC) showed a strong correlation amongst the CA, DA and SA for the total sample and gender; the correl-

Table 2: Correlation and comparison of chronological, dental and skeletal age of Yemeni children $(\mathrm{N}=358)$

$\begin{array}{lccccc}\text { Comparison } & & \text { Mean difference } \pm \text { SD } & \boldsymbol{P} \text { value* } & \text { ICC (95\% CI) } & P \text { value* } \\ \text { CA (total) } & \text { DA }(\mathrm{N}=358) & -0.58 \pm 1.25 & <0.001 & 0.923(0.906-0.938) & <0.001 \\ & \mathrm{SA}(\mathrm{n}=292)^{\dagger} & -0.23 \pm 1.19 & 0.02 & 0.882(0.852-0.906) & <0.001 \\ \text { CA (males) } & \mathrm{DA}(\mathrm{n}=193) & -0.73 \pm 1.30 & <0.001 & 0.915(0.888-0.936) & <0.001 \\ & \mathrm{SA}(\mathrm{n}=142)^{\dagger} & -0.44 \pm 1.26 & 0.001 & 0.831(0.765-0.879) & <0.001 \\ \text { CA (females) } & \mathrm{DA}(\mathrm{n}=165) & -0.40 \pm 1.17 & <0.001 & 0.935(0.911-0.952) & <0.001 \\ & \mathrm{SA}(\mathrm{n}=150)^{\dagger} & -0.02 \pm 1.08 & 0.898 & 0.917(0.885-0.940) & <0.001\end{array}$

$S D=$ standard deviation; $I C C=$ intraclass correlation coefficient $C I=$ confidence interval; $C A=$ chronological age; $D A=$ dental age; $S A=$ skeletal age. "Using the Wilcoxon signed-rank test and intraclass correlation coefficient. ${ }^{\dagger}$ Sample size varies from total due to exclusion of some children for not reaching the lower limit for analysis of the proximal phalanx of the third finger. 
Table 3: Comparison between chronological, dental and skeletal age for Yemeni children $(\mathrm{N}=358)$

\begin{tabular}{|c|c|c|c|c|c|c|}
\hline \multirow{2}{*}{$\begin{array}{l}\text { Age } \\
\text { group } \\
\text { in } \\
\text { years }\end{array}$} & \multirow[t]{2}{*}{ Gender } & \multicolumn{3}{|c|}{ Mean \pm SD } & \multicolumn{2}{|c|}{$P$ value } \\
\hline & & $\mathrm{CA}$ & DA & $\mathrm{SA}^{*}$ & $\begin{array}{c}\text { CA } \\
\text { versus } \\
\text { DA }\end{array}$ & $\begin{array}{c}\mathrm{CA} \\
\text { versus } \\
\mathrm{SA}\end{array}$ \\
\hline \multirow[t]{2}{*}{8} & $\begin{array}{c}M \\
(\mathrm{n}=21)\end{array}$ & $8.5 \pm 0.26$ & $8.28 \pm 0.8$ & $11.01 \pm 0^{\dagger}$ & 0.075 & $\mathrm{NC}$ \\
\hline & $\begin{array}{c}\mathrm{F} \\
(\mathrm{n}=23)\end{array}$ & $8.63 \pm 0.29$ & $8.22 \pm 0.9$ & $10.22 \pm 0.34^{\ddagger}$ & 0.048 & 0.008 \\
\hline \multirow[t]{2}{*}{9} & $\begin{array}{c}M \\
(n=17)\end{array}$ & $9.43 \pm 0.24$ & $8.79 \pm 0.99$ & $\mathrm{NA}^{\S}$ & 0.022 & NA \\
\hline & $\begin{array}{c}\mathrm{F} \\
(\mathrm{n}=18)\end{array}$ & $9.61 \pm 0.33$ & $9.74 \pm 1.09$ & $10.46 \pm 0.34$ & 0.616 & $<0.001$ \\
\hline \multirow[t]{2}{*}{10} & $\begin{array}{c}M \\
(n=28)\end{array}$ & $10.56 \pm 0.27$ & $9.90 \pm 1.09$ & $11.17 \pm 0.29$ & 0.003 & $<0.001$ \\
\hline & $\begin{array}{c}\mathrm{F} \\
(\mathrm{n}=21)\end{array}$ & $10.54 \pm 0.34$ & $10.35 \pm 1.16$ & $10.96 \pm 0.6$ & 0.715 & 0.002 \\
\hline \multirow[t]{2}{*}{11} & $\begin{array}{c}M \\
(\mathrm{n}=35)\end{array}$ & $11.48 \pm 0.27$ & $10.78 \pm 1.16$ & $11.58 \pm 0.42^{\|}$ & 0.004 & 0.357 \\
\hline & $\begin{array}{c}\mathrm{F} \\
(\mathrm{n}=24)\end{array}$ & $11.35 \pm 0.26$ & $10.58 \pm 1.13$ & $11.1 \pm 0.86$ & 0.002 & 0.17 \\
\hline \multirow[t]{2}{*}{12} & $\begin{array}{c}M \\
(n=29)\end{array}$ & $12.59 \pm 0.28$ & $11.52 \pm 1.37$ & $12.12 \pm 0.83$ & $<0.001$ & 0.005 \\
\hline & $\begin{array}{c}\mathrm{F} \\
(\mathrm{n}=22)\end{array}$ & $12.56 \pm 0.32$ & $12.06 \pm 1.09$ & $12.33 \pm 0.84$ & 0.02 & 0.095 \\
\hline \multirow[t]{2}{*}{13} & $\begin{array}{c}M \\
(n=21)\end{array}$ & $13.58 \pm 0.26$ & $13.29 \pm 1.54$ & $12.8 \pm 1.22$ & 0.394 & 0.017 \\
\hline & $\begin{array}{c}\mathrm{F} \\
(\mathrm{n}=21)\end{array}$ & $13.57 \pm 0.31$ & $13.45 \pm 1.22$ & $13.53 \pm 1.21$ & 0.781 & 0.689 \\
\hline \multirow[t]{2}{*}{14} & $\begin{array}{c}M \\
(n=16)\end{array}$ & $14.62 \pm 0.29$ & $13.66 \pm 1.47$ & $13.32 \pm 1.49$ & 0.026 & 0.005 \\
\hline & $\begin{array}{c}F \\
(n=14)\end{array}$ & $14.52 \pm 0.29$ & $14.09 \pm 1.47$ & $13.84 \pm 1.2$ & 0.433 & 0.096 \\
\hline \multirow[t]{2}{*}{15} & $\begin{array}{c}M \\
(n=26)\end{array}$ & $15.62 \pm 0.29$ & $14.53 \pm 1.51$ & $14.46 \pm 1.44$ & 0.004 & $<0.001$ \\
\hline & $\begin{array}{c}\mathrm{F} \\
(\mathrm{n}=22)\end{array}$ & $15.46 \pm 0.28$ & $14.81 \pm 1.31$ & $14.63 \pm 1.06$ & 0.036 & 0.001 \\
\hline
\end{tabular}

$S D=$ standard deviation; $C A=$ chronological age; $D A=$ dental age; $S A=$ skeletal age; $M=$ male $N C=$ not computed $F=$ female $N A=$ not applicable.

*Sample size may vary between age groups due to some children not reaching the lower limit for analysis of the proximal phalanx of the third finger. ${ }^{+} n=2 .{ }^{*} n=9$. ${ }^{\sharp}=0 .{ }^{\prime} n=17 . \quad{ }^{\prime} n=31$.

ation value was higher amongst females in both methods $(P<0.001$ each $)$ [Table 2].

There were significant differences found between CA and DA in all age groups $(P<0.05)$, except in the 13 -year-olds age group, the male 8 -year-olds age group and the female 9-, 10- and 14-year-olds age group. Significant differences between the CA and SA were found in all age groups, except in the 11-year-olds and the female 12-, 13- and 14-year-olds age groups. For the $\mathrm{SA}$, the males in the age groups 8 and 9 years were not compared as there were only two and zero males in these groups, respectively [Table 3].

The regression models showed very narrow confidence intervals for the intercept and slope, for both methods and both genders $(P<0.001)$ [Table 4]. During preliminary testing on the study sample, the models yielded adjusted $\mathrm{R}^{2}$ values of $71 \%$ and $78 \%$ for males and females, respectively, using the Demirjian method.
Table 4: Regression analysis using Demirjian and Fishman methods showing adjusted $\mathrm{R}^{2}$ amongst Yemeni children $(\mathrm{N}=358)$

$\begin{array}{ccccccccc}\text { Method } & \text { G } & \text { PARAM } & \text { COEF } & \text { SE } & \text { 95\% CI } & \begin{array}{c}P \\ \text { value }\end{array} & \begin{array}{c}\text { Adj. } \\ \mathbf{R}^{2}\end{array} \\ \text { Demirjian } & \text { M } & \text { Intercept } & 3.12 & 0.42 & 2.294-3.950 & <0.001 & \\ & & \text { Slope } & 0.79 & 0.04 & 0.718-0.861 & <0.001 & 0.71 \\ & & \text { F } & \text { Intercept } & 2.50 & 0.40 & 1.719-3.289 & <0.001 & \\ & & \text { Slope } & 0.82 & 0.03 & 0.751-0.884 & <0.001 & 0.78 \\ \text { Fishman } & \text { M } & \text { Intercept } & 9.21 & 0.19 & 8.833-9.589 & <0.001 & \\ & & \text { Slope } & 0.31 & 0.02 & 0.274-0.343 & <0.001 & 0.61 \\ & & \text { F } & \text { Intercept } & 7.14 & 0.36 & 6.431-7.846 & <0.001 & \\ & & \text { Slope } & 0.43 & 0.03 & 0.371-0.491 & <0.001 & 0.55\end{array}$

$G=$ gender $; P A R A M=$ parameter $; C O E F=$ coefficient $; S E=$ standard error: $C I=$ confidence intervals; Adj. = Adjusted; $M=$ male; $F=$ female

For the Fishman method, the regression models yielded adjusted $R^{2}$ values of $61 \%$ and $55 \%$ for males and females, respectively. The Dahlberg equation showed minimum error values ( 0.30 and 0.34 year) for the Demirjian and Fishman methods representing relative errors of $2.6 \%$ and $3.8 \%$, respectively. This showed that the two methods are highly reproducible.

\section{Discussion}

This study aimed to assess the validity of the Demirjian and Fishman methods in predicting the CA of Yemeni children. The results of the current study could aid clinical orthodontists in predicting the CA of children with no birth certificates and, therefore, appropriately timing intervention therapy to avoid the development of malocclusion.

In the current study, the Demirjian method appeared to be more accurate for females than for males when comparing CA to DA. The Demirjian method underestimated the CA for both genders with a higher deviation in males. This result indicates that Yemeni children are delayed in dental maturity relative to children from other regions. ${ }^{14} \mathrm{CA}$ underestimation and overestimation by the Demirjian method has been observed in other studies. ${ }^{11,23-25}$ However, the Demirjian method has shown applicability in other populations..$^{12,26}$ The differences in the obtained results amongst the different populations may be attributed to the statistical tests, sample size, age groups and study population. In the current study, the regression models used to predict the CA through DA estimated by the Demirjian method were highly significant.

Based on the results of this study, a high correlation coefficient value was found between the CA and SA, with a higher value in females than males; this finding is in agreement with previous studies. ${ }^{19,21}$ The Fishman method significantly overestimated CA for age groups 
of 8,9 and 10 years for females and age group of 10 years for males. This overestimation by the Fishman method may be attributed to the inability of the method to estimate the SA for children under 10 and 11 years of age for females and males, respectively.

Mohammed et al. found no significant difference between CA and SA amongst Indian females of 12, 13 and 14 years; this is in agreement with the current results. ${ }^{19}$ However, Saade et al. found a significant overestimation for the age groups of 8-16 years amongst Lebanese children; this differs from the current study's findings and may be attributed to the differences in sample size, group age intervals or other environmental and genetic factors. ${ }^{21}$ The variations amongst different populations may be partially attributed to methodological factors or to other factors, such as changes in socioeconomic condition or a large malnutritional range..$^{27,28}$ World Health Organization reported that Yemen is one of the top countries suffering from poor nutrition. ${ }^{29}$

The Demirjian and Fishman methods showed more accurate estimations amongst females than males. The biggest difference in mean CA amongst the age groups was observed with the Fishman method. The $\mathrm{R}^{2}$ for the line of best fit was higher with the Demirjian method than the Fishman method for both genders and the minimum constant value and highest slope value (closest to 1) were also found with the Demirjian method for both genders.

A one-year difference between CA and DA was considered acceptable for legal authorities and forensic purposes. ${ }^{30}$ Therefore, both the Demirjian and the Fishman method can be used for predicting the CA of Yemeni children with no birth certificate, for legal purposes such as school enrolment and marriage age determination as well as for forensic purposes. The Yemeni CA is not a strong diagnostic aid for assigning the proper timing for orthodontic growth modification by functional appliances.

The main limitation of this study is that the regression models used to predict the CA through SA and DA estimated by the Fishman and Demirjian methods, respectively, still need to be validated.

\section{Conclusions}

There is a strong correlation between CA and DA estimated by the Demirjian method and between CA and SA estimated by the Fishman method. However, both methods underestimated the CA of Yemeni children. Although the underestimation was less for females than for males, orthodontists should not rely on the CA of Yemeni children to assign the proper age for growth modification by functional appliances; however, SA is the more suitable method to allocate the correct timing for orthodontic functional treatment. Both the Demirjian and Fishman methods are considered acceptable for predicting the CA of Yemeni children with no birth certificate for legal, civil and forensic purposes.

\section{CONFLICT OF INTEREST}

The authors declare no conflicts of interest.

\section{FUNDING}

No funding was received for this study.

\section{References}

1. Krailassiri S, Anuwongnukroh N, Dechkunakorn S. Relationships between dental calcification stages and skeletal maturity indicators in Thai individuals. Angle Orthod 2002; 72:155-66.

2. Willems G. A review of the most commonly used dental age estimation techniques. J Forensic Odontostomatol 2001; 19:9-17.

3. Fishman LS. Radiographic evaluation of skeletal maturation. A clinically oriented method based on hand-wrist films. Angle Orthod 1982; 52:88-112.

4. Demirjian A, Goldstein H, Tanner JM. A new system of dental age assessment. Hum Biol 1973; 45:211-27.

5. Maber M, Liversidge HM, Hector MP. Accuracy of age estimation of radiographic methods using developing teeth. Forensic Sci Int 2006; 159 Suppl 1:S68-73. https://doi.org/10.1016/j.fors ciint.2006.02.019.

6. Apaydin BK, Yasar F. Accuracy of the Demirjian, Willems and Cameriere methods of estimating dental age on Turkish children. Niger J Clin Pract 2018; 21:257-63.

7. Hegde S, Patodia A, Dixit U. A comparison of the validity of the Demirjian, Willems, Nolla and Häävikko methods in determination of chronological age of 5-15 year-old Indian children. J Forensic Leg Med 2017; 50:49-57. https://doi.org/10.1016/j.jf $\operatorname{lm} .2017 .07 .007$.

8. Alshihri AM, Kruger E, Tennant M. Dental age assessment of 4-16 year old Western Saudi children and adolescents using Demirjian's method for forensic dentistry. Egypt J Forensic Sci 2016; 6:152-6. https://doi.org/10.1016/j.ejfs.2015.03.003.

9. Aissaoui A, Salem NH, Mougou M, Maatouk F, Chadly A. Dental age assessment among Tunisian children using the Demirjian method. J Forensic Dent Sci 2016; 8:47-51. https://doi.org/10. 4103/0975-1475.176956.

10. Qudeimat MA, Behbehani F. Dental age assessment for Kuwaiti children using Demirjian's method. Ann Hum Biol 2009; 36:695-704. https://doi.org/10.3109/03014460902988702.

11. Zhai Y, Park H, Han J, Wang H, Ji F, Tao J. Dental age assessment in a northern Chinese population. J Forensic Leg Med 2016; 38:43-9. https://doi.org/10.1016/j.jflm.2015.11.011.

12. Hasan BM, Abuaffan AH. Correlation between chronological age, dental age and skeletal maturity in a sample of Sudanese children. Global J Med Res 2016; 16:12-21.

13. Al Balushi S, Thomson WM, Al-Harthi L. Dental age estimation of Omani children using Demirjian's method. Saudi Dent J 2018; 30:208-13. https://doi.org/10.1016/j.sdentj.2018.04.005.

14. Jayaraman J, Wong HM, King NM, Roberts GJ. The FrenchCanadian data set of Demirjian for dental age estimation: A systematic review and meta-analysis. J Forensic Leg Med 2013; 20:373-81. https://doi.org/10.1016/j.jflm.2013.03.015. 
15. Kiran S, Sharma VP, Tandon P, Tikku T, Verma S, Srivastava K. To establish the validity of dental age assessment using Nolla's method on comparing with skeletal age assessed by hand-wrist radiographs. J Orthod Res 2013; 1:11-15. https://doi.org/10.41 03/2321-3825.112250.

16. Mansourvar M, Ismail MA, Raj RG, Kareem SA, Aik S, Gunalan R, et al. The applicability of Greulich and Pyle atlas to assess skeleta age for four ethnic groups. J Forensic Leg Med 2014; 22:26-9. https://doi.org/10.1016/j.jflm.2013.11.011.

17. Flores-Mir C, Nebbe B, Major PW. Use of skeletal maturation based on hand-wrist radiographic analysis as a predictor of facial growth: A systematic review. Angle Orthod 2004; 74:118-24.

18. Soegiharto BM, Moles DR, Cunningham SJ. Discriminatory ability of the skeletal maturation index and the cervical vertebrae maturation index in detecting peak pubertal growth in Indonesian and white subjects with receiver operating characteristics analysis. Am J Orthod Dentofacial Orthop 2008; 134:227-37. https://doi.org/10.1016/j.ajodo.2006.09.062.

19. Mohammed RB, Kalyan VS, Tircouveluri S, Vegesna GC, Chirla A Varma DM. The reliability of Fishman method of skeletal maturation for age estimation in children of South Indian population. J Nat Sci Biol Med 2014; 5:297-302. https://doi.org/10.4103/09 76-9668.136170.

20. Soegiharto BM, Cunningham SJ, Moles DR. Skeletal maturation in Indonesian and white children assessed with hand-wrist and cervical vertebrae methods. Am J Orthod Dentofacial Orthop 2008; 134:217-26. https://doi.org/10.1016/j.ajodo.2006.07.037.

21. Saadé A, Baron P, Noujeim Z, Azar D. Dental and skeletal age estimations in Lebanese children: A retrospective cross-sectional study. J Int Soc Prev Community Dent 2017; 7:90-7.

22. Kırzıoğlu Z, Ceyhan D. Accuracy of different dental age estimation methods on Turkish children. Forensic Sci Int 2012; 216:61-7. https://doi.org/10.1016/j.forsciint.2011.08.018
23. Cruz-Landeira A, Linares-Argote J, Martínez-Rodríguez M, Rodríguez-Calvo MS, Otero XL, Concheiro L. Dental age estimation in Spanish and Venezuelan children. Comparison of Demirjian and Chaillet's scores. Int J Legal Med 2010; 124:105-12. https://doi.org/10.1007/s00414-009-0380-5.

24. Mani SA, Naing L, John J, Samsudin AR. Comparison of two methods of dental age estimation in 7-15-year-old Malays. Int J Paediatr Dent 2008; 18:380-8. https://doi.org/10.1111/j.1365263X.2007.00890.x.

25. Gungor OE, Kale B, Celikoglu M, Gungor AY, Sari Z. Validity of the Demirjian method for dental age estimation for Southern Turkish children. Niger J Clin Pract 2015; 18:616-19. https://doi.org/10.4103/1119-3077.154216.

26. Burt NM, Sauer N, Fenton T. Testing the Demirjian and the international Demirjian dental aging methods on a mixed ancestry urban American subadult sample from Detroit, MI. J Forensic Sci 2011; 56:1296-301. https://doi.org/10.1111/j.15564029.2011.01833.x

27. Ozer BK. Growth reference centiles and secular changes in Turkish children and adolescents. Eco Hum Biol 2007; 5:280-301. https://doi.org/10.1016/j.ehb.2007.03.007.

28. Garn SM, Lewis AB, Kerewsky RS. Genetic, nutritional, and maturational correlates of dental development. J Dent Res 1965; 44:228-42. https://doi.org/10.1177/00220345650440011901.

29. World Health Organization. Annual report 2017-Yemen. Cairo, Egypt: World Health Organization Regional Office for the Eastern Mediterranean 2018. CC BYNC-SA 3.0 IGO P. 22.

30. Chaillet N, Nyström M, Kataja M, Demirjian A. Dental maturity curves in Finnish children: Demirjian's method revisited and polynomial functions for age estimation. J Forensic Sci 2004; 49:1324-31. https://doi.org/10.1520/JFS2004211. 